\title{
Efficacy And Safety Of Controlled-Release Oxycodone For The Management Of Moderate-To-Severe Chronic Non-Cancer Pain In Japanese Patients: Results From An Open-Label Study
}

This article was published in the following Dove Press journal: Journal of Pain Research

\author{
Mikito Kawamata $\mathbb{D}^{\prime}$ \\ Masako Iseki iD ${ }^{2}$ \\ Mamoru Kawakami iD ${ }^{3}$ \\ Shoji Yabuki (D) ${ }^{4}$ \\ Takuma Sasaki ${ }^{5}$ \\ Mitsuhiro Ishida (iD ${ }^{5}$ \\ Atsushi Nishiyori ${ }^{5}$ \\ Hideaki Hida ${ }^{6}$ \\ Shin-ichi Kikuchi ${ }^{4}$ \\ 'Department of Anesthesiology and \\ Resuscitology, Shinshu University School \\ of Medicine, Matsumoto, Japan; \\ ${ }^{2}$ Department of Anesthesiology and Pain \\ Medicine, Juntendo University Faculty of \\ Medicine, Tokyo, Japan; ${ }^{3}$ Spine Care \\ Center, Wakayama Medical University \\ Kihoku Hospital, Wakayama, Japan; \\ ${ }^{4}$ Department of Orthopaedic Surgery, \\ Fukushima Medical University School of \\ Medicine, Fukushima, Japan; ${ }^{5}$ Clinical \\ Development Department, Shionogi \& \\ Co., Ltd., Osaka, Japan; ${ }^{6}$ Biostatistics \\ Center, Shionogi \& Co., Ltd., Osaka, \\ Japan
}

Purpose: To assess the efficacy and safety of S-8117, an oral, controlled-release formulation of oxycodone hydrochloride, in Japanese patients with chronic non-cancer pain (CNCP).

Patients and methods: In this multicenter, non-randomized, open-label, 2-part (part 1, dosetitration followed by maintenance period; part 2, long-term administration period) study at 38 centers in Japan (2013-2015), adult patients with CNCP for $\geq 12$ weeks were administered S-8117. The primary endpoint was proportion of patients with successful maintenance of pain control in part 1 and long-term safety in part 2. Secondary endpoints included time to inadequate analgesia, rate of transition to the maintenance period, and discontinuation due to inadequate analgesia/ adverse events (AEs), Brief Pain Inventory (BPI) pain severity, BPI pain interference, 36-item Short Form Health Survey (SF-36) score, and Western Ontario and McMaster Universities (WOMAC) index, Subjective Opioid Withdrawal Scale (SOWS), Clinical Opioid Withdrawal Scale (COWS), Dependency-2-A (D-2-A), and Dependency-2-B (D-2-B) questionnaires.

Results: Of 130 patients (mean age, 63.6 years; women, $62.3 \%$ ) in the dose-titration period, 95 entered the maintenance period; 60 of 83 who entered the long-term administration period completed it. The proportion of patients ( $95 \%$ confidence interval) with successful maintenance of pain control, transition to maintenance period, and discontinuation due to inadequate analgesia/AEs was 78.9\% (69.4-86.6), 73.1\% (64.6-80.5), and 21.1\% (13.4-30.6), respectively. Time to inadequate analgesia could not be estimated. Changes from baseline in BPI, SF-36, and WOMAC index scores suggested improvements in pain relief and quality of life. Based on the SOWS, COWS, D-2-A and D-2-B questionnaires, no patient developed clinically relevant withdrawal syndrome or was ascertained to have developed drug dependence. Overall, the incidence of treatment-emergent AEs (TEAEs) was 93.8\%; most common TEAEs were constipation (49.2\%), nausea (42.3\%), nasopharyngitis (34.6\%), and somnolence (32.3\%).

Conclusion: These results demonstrate the efficacy and safety of S-8117 in Japanese patients with $\mathrm{CNCP}$

Keywords: analgesics, chronic pain, Japan, opioids

\section{Introduction}

Chronic pain is reportedly prevalent in Japan as well as Western countries such as the United States (US) and Canada. ${ }^{1-3}$ Recent studies in Japan have suggested that chronic pain is not only associated with a worsening of a patient's quality of life
Correspondence: Takuma Sasaki Clinical Development Department, Shionogi \& Co., Ltd., I2F, Hankyu Terminal Bld., I-4, Shibata I-chome, Kitaku, Osaka 530-0012, Japan

Tel +8I-6-6485-5090

Fax +8I-6-6375-5780

Email Takuma.sasaki@shionogi.co.jp 
(QOL) but also leads to economic loss due to a decrease in work productivity. ${ }^{4-6}$ The goal of chronic pain management is to improve QOL and activities of daily living; opioids are one of the treatment options available to achieve these outcomes. ${ }^{7}$

Although opioids are indicated for the management of chronic non-cancer pain (CNCP) due to their potent analgesic effect, they are not recommended as primary or preferred treatment options since their use could lead to overdosing, abuse, or misuse among patients. $^{\text {7-9 }}$ Moreover, opioids are associated with a high risk of adverse drug reactions such as nausea, constipation, somnolence, and respiratory depression. ${ }^{10}$

In Japan, strong opioids that are indicated for CNCP are currently limited to morphine (oral rapid-release formulation and injection) and fentanyl patches. ${ }^{7}$ The Narcotics and Psychotropics Control Act of Japan stipulates that most opioids, designated as narcotics, must be prescribed solely by doctors with opioid prescription license and that records for the transfer of opioids should be maintained throughout the entire distribution process, ${ }^{11}$ thereby ensuring that the opioid management system is more tightly regulated than in Western countries. Moreover, evidence suggests that physicians in Japan are more cautious about the use of medical narcotics and less enthusiastic about prescribing them compared to those in the US. ${ }^{12}$ This is likely the reason for the extremely low rate of overdose-related admissions reported in Japan from October 2012 through September $2013^{13}$ compared with overdose-related emergency admissions in the US. ${ }^{14}$ However, strict control and avoidance of opioid use could potentially limit options for management of patients with chronic pain in Japan.

S-8117 (OxyContin ${ }^{\circledR}$ tablets, Purdue Pharma LP, Stamford, CT, USA) is an oral, controlled-release (CR) formulation containing oxycodone hydrochloride as an active ingredient. ${ }^{15}$ Oxycodone offers similar levels of analgesic efficacy to morphine, ${ }^{16}$ and its active metabolite is less likely to accumulate in the body than active morphine metabolites in patients with impaired renal function. ${ }^{17}$ Worldwide, S-8117 is one of the most commonly used strong opioids for the treatment of moderate-to-severe pain. In Japan, it is also the most commonly prescribed strong opioid for the treatment of cancer pain. Previous studies have demonstrated the analgesic effects of CR oxycodone hydrochloride tablets for various types of moderateto-severe pain. ${ }^{18-21}$ However, as with other strong opioids, the use of oxycodone hydrochloride tablets was associated with dependence or abuse in the US. ${ }^{22,23}$ In order to avoid abuse of oxycodone, OxyContin ${ }^{\circledR}$ tablets have been reformulated in an abuse-deterrent formulation ${ }^{24}$ that became available in the US in 2010 and in Japan in 2017. Nevertheless, in Japan, oxycodone formulations (both abuse-deterrent and non-abuse-deterrent) are not indicated for $\mathrm{CNCP}^{7}$ and their safety and efficacy has not yet been established in patients with CNCP.

We have previously reported results from a placebocontrolled, enriched enrollment, randomized, withdrawal study and its open-label extension that assessed the efficacy and safety of S-8117, a conventional, non-abusedeterrent oxycodone formulation, in Japanese patients with chronic low back pain (CLBP). ${ }^{25}$ The enriched enrollment, randomized, withdrawal study demonstrated the short-term efficacy versus placebo of S-8117 in the management of Japanese patients with moderate-to-severe CLBP. Furthermore, in the extension study, S-8117 was well tolerated for approximately 1 year of continuous administration. However, the safety and efficacy of S-8117 in Japanese patients suffering from CNCP due to other underlying conditions have not been investigated. Consequently, the purpose of this phase 3 study was to confirm the efficacy and safety of S-8117 in patients with $\mathrm{CNCP}$ due to various other underlying conditions. We selected osteoarthritis (OA), diabetic neuropathic pain (DNP), and post-herpetic neuralgia (PHN) as the most common CNCP conditions and also included patients with other CNCP conditions. Due to safety concerns related to opioid use, the target patient population was limited to those patients who required treatment with S-8117 under routine clinical practice. Therefore, patients who continued to experience pain despite treatment with non-opioid or weak opioid analgesics and those receiving treatment with strong opioids were included in this study.

This study aimed to assess the efficacy and safety of oxycodone in patients with moderate-to-severe $\mathrm{CNCP}$ as a whole but did not aim to compare its efficacy or safety across underlying pain conditions such as OA, DNP, and PHN.

\section{Materials And Methods Study Design}

This was a phase 3 , multicenter, non-randomized, openlabel study conducted from May 2013 to June 2015 at 38 centers in Japan. Patients were followed for 8 to 57 weeks or until discontinuation. The study consisted of two parts 
(Figure 1). In part 1, all enrolled patients entered the dosetitration period (14-28 days; maximum 32 days) followed by a 35-day maintenance period if they met the transition criteria on or after day 15 . In order to transition to the maintenance period, the prescribed dose of S-8117 should have remained the same for 7 days before the evaluation day, and the following criteria were required to be met for 3 days prior to the evaluation day: Brief Pain Inventory (BPI) $24 \mathrm{hr}$ average pain severity score of $\leq 3$, or improvement by $30 \%$ or greater from baseline; no additions or changes in the administration and/or dosage of non-opioid analgesics (excluding treatment for adverse events [AEs] such as fever) and adjuvant analgesics (except dose reduction); and that AEs were well tolerated.

Patients who completed part 1 of the study and were willing to continue transitioned to part 2 of the study comprising a 46-week long-term administration period. All patients including those who completed the long-term administration period or discontinued the study after part 1 or were not willing to continue or did not receive treatment with other opioid analgesics after discontinuation entered a 7-day dose-tapering period followed by a 7-day post-treatment observation period. The dose-tapering period could be extended to 14 days, based on investigator discretion (Figure 1).

This study is registered with the Japan Pharmaceutical Information Center Clinical Trials Information (JapicCTI) registry (JapicCTI-132081).

\section{Rationale For The Study Design}

The open-label design was chosen to mimic clinical settings to evaluate the efficacy and long-term safety of S-8117 in Japanese patients with $\mathrm{CNCP}$ due to various underlying conditions. A dose-titration period was included to individualize the optimal dose of S-8117 and confirm tolerability to the drug for efficacy evaluation. According to neurological treatment guidance for chronic pain, ${ }^{26}$ maintenance of the analgesic effect of a drug should be evaluated after 3 to 4 weeks of dose maintenance period following a gradual dose increase to a maximum; a 28-day maintenance period was considered appropriate for this study. However, in the previously reported double-blind study in patients with $\mathrm{CLBP}^{25}$ an additional 7 days were included for both S-8117 and placebo groups to avoid any withdrawal symptoms. Therefore, the maintenance period was set at 35 days in alignment with that study.

\section{Patient Criteria}

Adult patients aged 20 to $<80$ years, with chronic pain for $\geq 12$ weeks associated with OA, DNP, PHN, or other CNCP conditions, who could provide written informed consent, were included in the study. Other key inclusion criteria were (i) a $\mathrm{BPI}^{27} 24 \mathrm{hr}$ average pain severity score of $\geq 4$ despite treatment with non-opioid analgesics (oral/patch/suppository) including adjuvant analgesics, oral tramadol, oral codeine (dose $\leq 800$ $\mathrm{mg}$ /day), or buprenorphine patch for $\geq 14$ days, and (ii) treatment with morphine (dose $\leq 120 \mathrm{mg} /$ day) or fentanyl patch (dose release $\leq 100 \mu \mathrm{g}$ /hour) for $\geq 14$ days irrespective of any

Part 1

Part 2

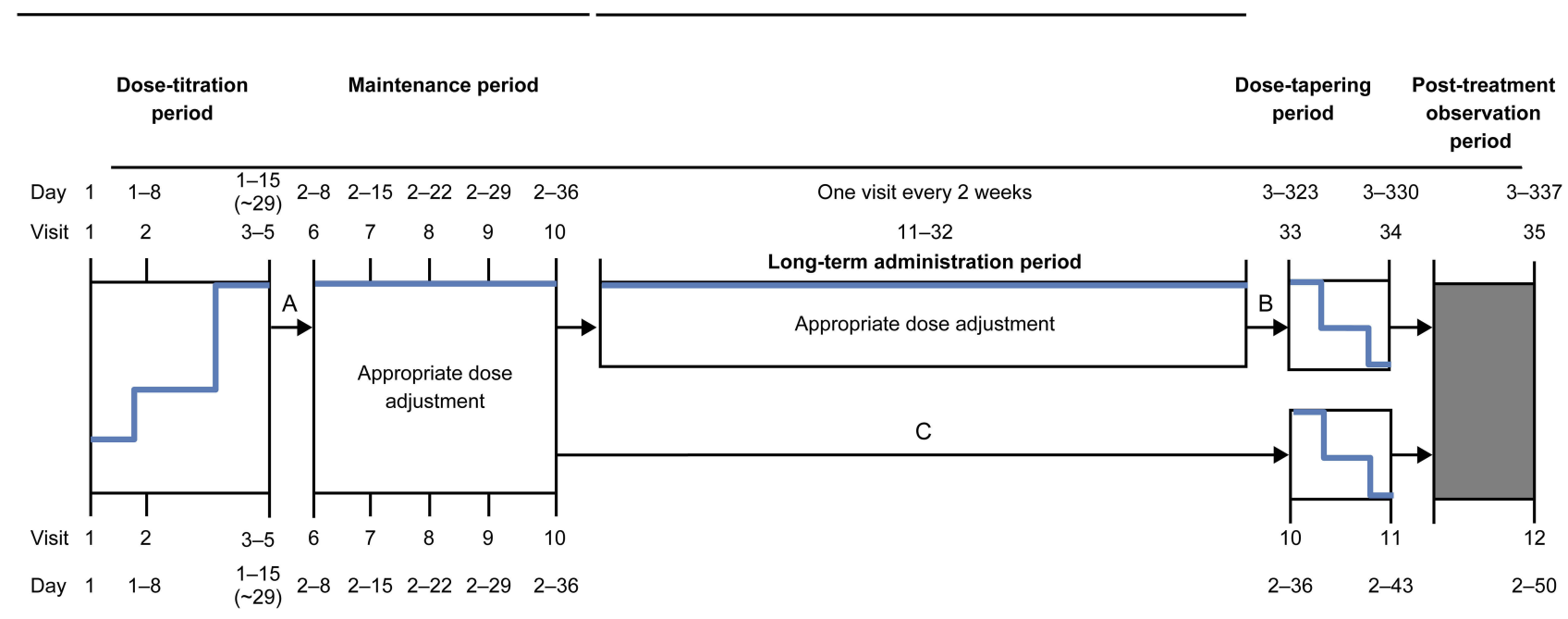

Figure I Study design.

Notes: (A) Patients who met the maintenance phase transition criteria. (B) Patients who completed the long-term administration period or did not receive treatment with other opioid analgesics after discontinuation. (C) Patients who did not transition to part 2 after the maintenance period or did not receive treatment with other opioid analgesics after discontinuation. 
BPI pain severity score. Patients with psychogenic pain as the primary cause of CNCP (based on investigator discretion); patients diagnosed with and receiving treatment for psychiatric disorders (eg, depression and schizophrenia); patients with a Brief Scale for Psychiatric Problems in Orthopaedic Patients (BS-POP) ${ }^{28}$ score of $\geq 11$; patients with a past history of drug abuse/drug dependence/alcohol dependence or confirmed/suspected abuse or dependence; or patients positive for phencyclidine, cocaine, stimulants, or cannabis in urinary drug testing, and confirmed by the investigator, were excluded from the study.

\section{Study Drug Administration}

The starting dose of S-8117 was $5 \mathrm{mg} /$ single dose in patients who were previously not using any opioid analgesics. In patients who were previously using opioid analgesics, the S-8117 dose was selected according to the dose of the previous analgesic, and half of the selected dose was orally administered twice daily. In the dose-titration period, a dose increase in the order of $5 \mathrm{mg}, 10 \mathrm{mg}, 20 \mathrm{mg}, 30 \mathrm{mg}$, and $40 \mathrm{mg}$ (10 mg increment for a single dose $>40 \mathrm{mg}$ ) was permitted if the BPI $24 \mathrm{hr}$ average pain severity score did not improve to $\leq 3$, or by $\geq 30 \%$ from baseline. In the maintenance period, patients continued with the dose that was being administered at the end of the dose-titration period. Worsening of pain was considered as inadequate analgesia and the dose was increased accordingly. Dose reductions were based on the discretion of the investigator in the event of the onset of non-tolerable AEs, which may or may not be related to a dose increase. In the long-term administration period, patients continued with the dose that was being administered at the end of the maintenance phase in part 1. A dose increase ( $5 \mathrm{mg}$ per single dose) or reduction was permitted in case of worsening of pain and onset of AEs, respectively.

In any study period, a dose increase by $10 \mathrm{mg}$ each time and by $20 \mathrm{mg}$ each time for a single dose of $\geq 10 \mathrm{mg}$ and $\geq 20 \mathrm{mg}$, respectively, was permitted depending on symptoms. However, a dose increase was not permitted within 3 days from the start of drug administration or within 3 days following the previous dose increase or if $<6$ doses were administered. Dose reduction was permitted based on the discretion of the investigator.

\section{Study Assessments Efficacy Assessment}

In part 1 of the study, the primary efficacy endpoint was the proportion of patients with successful maintenance of pain control, assessed by the proportion of patients without inadequate analgesia. Patients were assessed to have inadequate analgesia with S-8117 during the maintenance period if they met one of the following criteria: (i) worsened pain due to their underlying condition that resulted in a dose increase, a change in the analgesic (or a dose reduction or discontinuation), or addition of another analgesic (including rescue treatment that excluded treatment for $\leq 3$ consecutive days for AEs, such as fever) or (ii) BPI $24 \mathrm{hr}$ average pain severity score did not improve to $\leq 3$, or improvement was not $\geq 30 \%$ for 3 consecutive days from the time of enrollment. The secondary efficacy endpoints in part 1 and 2 of the study included the time to inadequate analgesia during the maintenance period, rate of transition to the maintenance period, and the proportion of patients who discontinued due to inadequate analgesia or AEs, BPI pain severity, BPI pain interference, 36-item Short Form Health Survey (SF-36) score, $^{29}$ and the Western Ontario and McMaster Universities (WOMAC) $\mathrm{OA}$ index ${ }^{30}$ (only in patients with OA).

\section{Safety Assessment}

In part 2 of the study, the primary endpoint was the longterm safety of S-8117, assessed by the incidence of treatment-emergent AEs (TEAEs) and serious TEAEs. The incidence of TEAEs and serious TEAEs was also assessed in part 1 of the study as a secondary endpoint. Other secondary safety endpoints in parts 1 and 2 of the study, in patients who did not receive treatment with other opioid analgesics after study discontinuation or after completing the maintenance or long-term administration periods, were presence/absence of withdrawal symptoms, assessed using the Subjective Opioid Withdrawal Scale (SOWS) ${ }^{31}$ and the Clinical Opioid Withdrawal Scale (COWS) ${ }^{32}$ and drug dependency assessed by the Dependency-2-A (D-2-A) and Dependency-2-B (D-2-B) questionnaires. ${ }^{33}$

\section{Assessment Measures And Schedule}

BPI pain severity items (worst, least, average, and current pain) in the previous $24 \mathrm{hrs}$ were rated on a scale of 0 (no pain) to 10 (pain as bad as one can imagine) and documented in a paper-based diary by patients daily before the morning dose and were confirmed and recorded by the investigator at each study visit (visits $1-10$ in part 1; visits 11-33 in part 2). BPI pain interference items (general activity, mood, walking ability, normal work, relationship with others, sleep, and enjoyment of life) were rated on a scale of 0 (does not interfere) to 10 (completely interferes) 
at each visit (visits 1-10 in part 1; visits $11-33$ in part 2), and confirmed and recorded by the investigator. BPI pain severity and BPI pain interference items were also recorded at the end of the dose-tapering period for patients not transitioning to the long-term administration period and for those who did not undergo treatment with other opioid analgesics after the long-term administration period. SF-36 score was evaluated based on patients' answers to 36 questions categorized into eight health subscales: physical functioning, role physical, bodily pain, general health, vitality, social functioning, role emotional, and mental health, confirmed by the investigator and recorded on visits 1,5 (or when the patient met the transition criteria for the maintenance period), and 10 in part 1 and on visits 22 and 33 in part 2 of the study. The WOMAC score was evaluated based on patients' answers to 24 questions structured in three sections of pain, stiffness, and physical function on visits 1, 5 (or when the patient met the transition criteria for maintenance period), and 10 in part 1 and on visits 16, 22, 28, and 33 in part 2 of the study. In addition, all scores were recorded at the time of discontinuation.

Safety was assessed at each visit from visit 1 onwards to the end of the post-treatment observation period. Patients rated their feelings every day on a 5-level (0 [not at all] to 4 [strongly]) SOWS starting from visit 10 (or discontinuation) in part 1 and visit 33 (discontinuation) in part 2 of the study until the end of post-treatment observation period. Investigators rated 11 symptoms (resting pulse rate, sweating, restlessness, pupil size, bone/joint pain, runny nose/tearing, gastrointestinal upset, tremors, yawning, anxiety/irritability, gooseflesh) on the 3- to 5-level COWS on visit 10 (or discontinuation) in part 1 and visit 33 (or discontinuation) in part 2, end of tapering period, and post-treatment observation period. Similarly, patients rated their feelings on a 4-level scale (0 [none], 1 [slight], 2 [moderate], or 3 [remarkable]) on the D-2-A questionnaire on visit 10 (or discontinuation) in part 1 and visits $14,18,22,26,30$, and 33 (or discontinuation) in part 2 , and the D-2-B questionnaire at the end of post-treatment observation phase (Table S1). All patient-rated assessments were confirmed by the investigator.

\section{Statistical Analysis}

The target sample size was 130 patients with chronic pain, including 30 patients with OA, 10 patients with DNP, and 10 patients with PHN. Approximately 90 patients were targeted to transition to the maintenance phase, taking into consideration a dropout rate of approximately $30 \%$ at the time of transition. The full analysis set (FAS) comprised patients who received at least one dose of S-8117 and had BPI pain severity data assessed at baseline and on at least one visit after the start of treatment. FAS- 2 comprised patients who transitioned to the maintenance period, received at least one dose of S-8117, and had BPI pain severity data assessed on at least one visit in the maintenance period.

AEs were coded using the Medical Dictionary for Regulatory Activities version 18.0 and summarized by system organ class and preferred term.

The Clopper-Pearson method was used to estimate the 95\% confidence interval (CI) for the primary endpoint (proportion of patients with successful maintenance of pain control), proportion of patients with transition to the maintenance period, and proportion of patients who discontinued due to inadequate analgesia or AEs. The two-sided 95\% CI for the proportion of patients without inadequate analgesia during the maintenance period was estimated using the Kaplan-Meier (KM) method. As this was an open-label study, no statistical comparison was performed. All statistical analyses were performed using SAS software version 9.2 (SAS Institute Inc., Cary, NC, USA).

\section{Results}

\section{Patient Disposition}

A total of 130 patients were enrolled in the study (Figure 2). This included 56, 11, 28, and 35 patients with OA, DNP, PHN, and other CNCP conditions (complex regional pain syndrome, $\mathrm{n}=9$, prolonged postoperative pain, $\mathrm{n}=3$; post-thoracotomy pain syndrome, $n=2$; rest of the conditions in 1 patient each, $\mathrm{n}=21$ ), respectively. The FAS and safety analysis set included all 130 patients, while the FAS-2 included 95 patients. All 130 patients entered the dose-titration period; of these, 35 discontinued, with the most common reason being AEs in 15 patients. Of the 95 patients who transitioned to the maintenance period, 92 completed, with 3 patients discontinuing due to patient's request, AEs, and inadequate analgesia. Overall, 83 patients transitioned to, and 60 patients completed, the long-term administration period. The most common reason for discontinuation during this period was AEs in 13 patients (Figure 2).

\section{Baseline Demographics And Characteristics}

Overall, $56.2 \%$ of the enrolled patients were aged 65 to $<80$ years (mean \pm standard deviation [SD] age, $63.6 \pm 11.3$ 


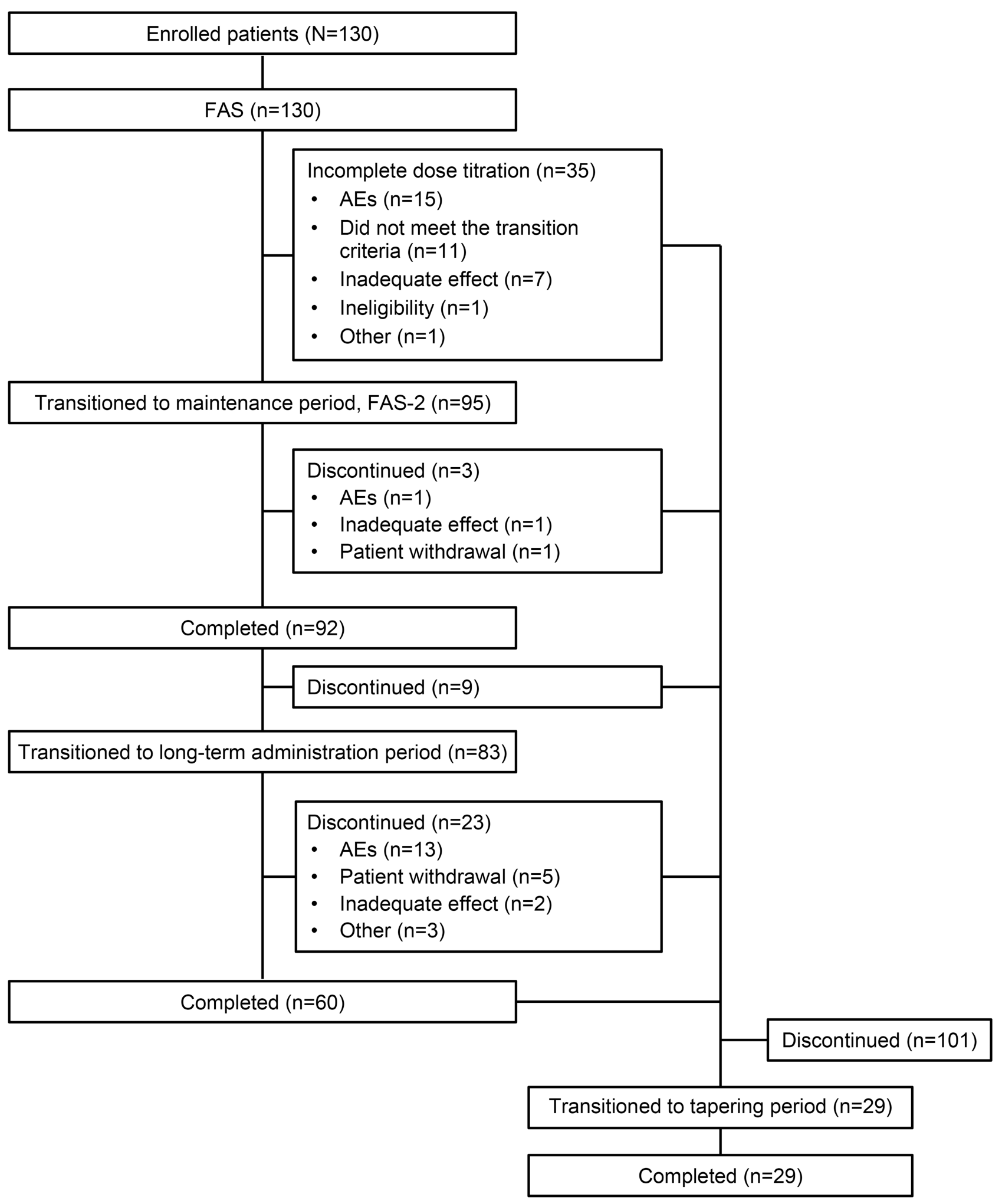

Figure 2 Patient disposition.

Abbreviations: $\mathrm{AE}$, adverse event; FAS, full analysis set.

years) and $62.3 \%$ were women. The majority (98.5\%) of patients were treated in outpatient settings. The most commonly used prior opioid analgesic was tramadol (51.5\%).
However, the majority $(81.8 \%, \mathrm{n}=9)$ of patients with DNP $(n=11)$ were not taking any opioid analgesics prior to enrollment (Table 1). 
Table I Baseline Demographics And Characteristics (Safety Analysis Set)

\begin{tabular}{|c|c|c|c|c|c|}
\hline Characteristics & $\begin{array}{l}\text { Total } \\
(n=130)\end{array}$ & $\begin{array}{l}\text { Osteoarthritis } \\
(n=56)\end{array}$ & $\begin{array}{l}\text { Diabetic } \\
\text { Neuropathic Pain } \\
(n=I I)\end{array}$ & $\begin{array}{l}\text { Post-Herpetic } \\
\text { Neuralgia }(n=28)\end{array}$ & $\begin{array}{l}\text { Other Chronic Pain } \\
\text { Conditions }(n=35)\end{array}$ \\
\hline Age, 65 to $<80$ years, $n(\%)$ & $73(56.2)$ & $28(50.0)$ & $8(72.7)$ & $26(92.9)$ & II (3I.4) \\
\hline Age, years, mean $\pm S D$ & $63.6 \pm 11.3$ & $63.6 \pm 9.4$ & $65.1 \pm 10.4$ & $72.6 \pm 4.9$ & $55.9 \pm 12.9$ \\
\hline Sex, female, n (\%) & $81(62.3)$ & $42(75.0)$ & $4(36.4)$ & $16(57.1)$ & $19(54.3)$ \\
\hline Outpatient, n (\%) & $128(98.5)$ & $56(100.0)$ & $10(90.9)$ & $28(100.0)$ & $34(97.1)$ \\
\hline Height, $\mathrm{cm}$, mean $\pm S D$ & $158.0 \pm 10.0$ & $157.7 \pm 7.7$ & $158.8 \pm 7.4$ & $157.4 \pm 9.4$ & $|58.7 \pm| 4 . \mid$ \\
\hline Weight, kg, mean \pm SD & $61.9 \pm 11.7$ & $64.6 \pm 11.5$ & $64.5 \pm 13.2$ & $56.9 \pm 10.2$ & $60.3 \pm 11.8$ \\
\hline \multicolumn{6}{|l|}{ Prior opioid analgesics, n (\%) } \\
\hline Morphine & $5(3.8)$ & 0 & 0 & $2(7.1)$ & $3(8.6)$ \\
\hline Codeine & $4(3.1)$ & 0 & I (9.I) & $3(10.7)$ & 0 \\
\hline Fentanyl & $23(17.7)$ & $4(7.1)$ & 0 & $8(28.6)$ & II (3I.4) \\
\hline Buprenorphine & $2(1.5)$ & $\mathrm{I}(\mathrm{I} .8)$ & 0 & 0 & I (2.9) \\
\hline Tramadol & $67(51.5)$ & $44(78.6)$ & I (9.1) & $10(35.7)$ & $12(34.3)$ \\
\hline No opioid analgesics & $29(22.3)$ & $7(12.5)$ & $9(81.8)$ & $5(17.9)$ & $8(22.9)$ \\
\hline $\begin{array}{l}\text { Significant previous medical } \\
\text { condition, } \mathrm{n}(\%)\end{array}$ & $8(6.2)$ & $2(3.6)$ & $4(36.4)$ & $2(7.1)$ & 0 \\
\hline Comorbidities, n (\%) & $124(95.4)$ & $51(91.1)$ & II $(100.0)$ & $28(100.0)$ & $34(97.1)$ \\
\hline
\end{tabular}

Abbreviation: SD, standard deviation.

\section{Efficacy}

During the maintenance period, the proportion of patients with successful maintenance of pain control was $78.9 \%$ (95\% CI 69.4-86.6) (Table 2). A similar proportion of patients showed successful maintenance of pain control across the various CNCP conditions (76.2-87.5\%; Table 2). The proportion of patients without inadequate analgesia during the maintenance period, estimated by KM analysis, was $78.8 \%$ (95\% CI 69.1-85.8) and was comparable across CNCP conditions (OA, 76.2\%; DNP, 87.5\%; PHN, $80.0 \%$; other CNCP conditions, $78.9 \%$ ). However, time to inadequate analgesia during the maintenance period could not be estimated from the KM analysis. The proportion of patients with transition to the maintenance period was $73.1 \%$ (95\% CI 64.6-80.5). This was numerically lower in patients with other $\mathrm{CNCP}$ conditions (57.1\%) but was not greatly different to that observed in the additional CNCP conditions (OA, 75.0\%; DNP, 72.7\%; PHN, 89.3\%). Overall, 21.1\% (95\% CI 13.4-30.6) of patients discontinued due to inadequate analgesia or AEs, with similar proportion across all CNCP conditions (OA, 23.8\%; DNP, 12.5\%; PHN, 20.0\%; other CNCP conditions, $20.0 \%$ ).

The mean scores for the four BPI pain severity items (Figure 3) and BPI pain interference for seven daily activities decreased numerically from baseline to the end of the dose-titration period and at the last observation of the maintenance and long-term administration periods,

Table 2 Patients With Successful Maintenance Of Pain Control During The Maintenance Period (FAS-2)

\begin{tabular}{|l|l|l|l|l|l|}
\hline Variables & $\begin{array}{l}\text { Total } \\
(\mathbf{n = 9 5 )}\end{array}$ & $\begin{array}{l}\text { Osteoarthritis } \\
(\mathbf{n = 4 2 )}\end{array}$ & $\begin{array}{l}\text { Diabetic } \\
\text { Neuropathic } \\
\text { Pain (n=8) }\end{array}$ & $\begin{array}{l}\text { Post-Herpetic } \\
\text { Neuralgia } \\
(\mathbf{n = 2 5})\end{array}$ & $\begin{array}{l}\text { Other Chronic Pain } \\
\text { Conditions (n=20) }\end{array}$ \\
\hline $\begin{array}{l}\text { Number of patients with successful } \\
\text { maintenance of pain control }\end{array}$ & 75 & 32 & 7 & 20 & 16 \\
\hline $\begin{array}{l}\text { Proportion of patients with successful } \\
\text { maintenance of pain control (\%) }\end{array}$ & 78.9 & 76.2 & 87.5 & 80.0 & 80.0 \\
\hline$[95 \% \mathrm{Cl}]$ & {$[69.4-86.6]$} & {$[60.5-87.9]$} & {$[47.3-99.7]$} & {$[59.3-93.2]$} & {$[56.3-94.3]$} \\
\hline
\end{tabular}

Notes: The $95 \% \mathrm{Cl}$ was calculated using the Clopper-Pearson method.

Abbreviations: $\mathrm{Cl}$, confidence interval; FAS, full analysis set. 
A

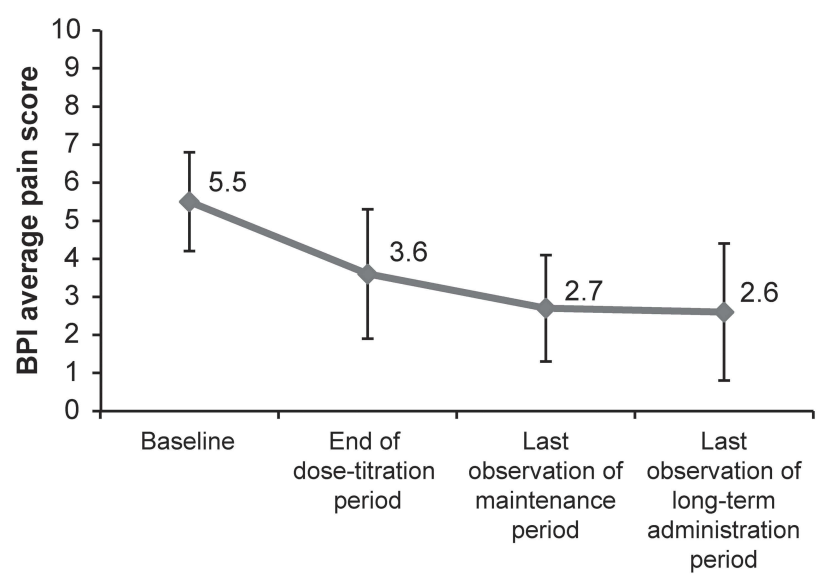

C

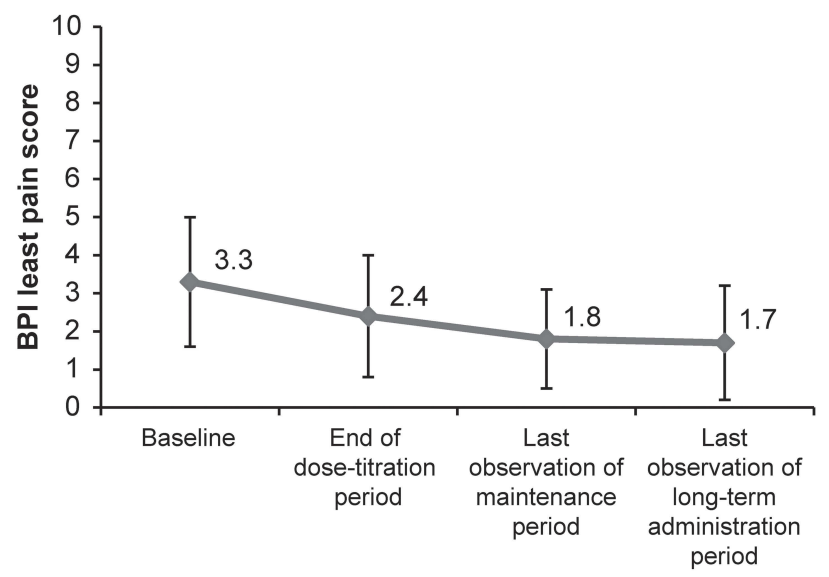

B

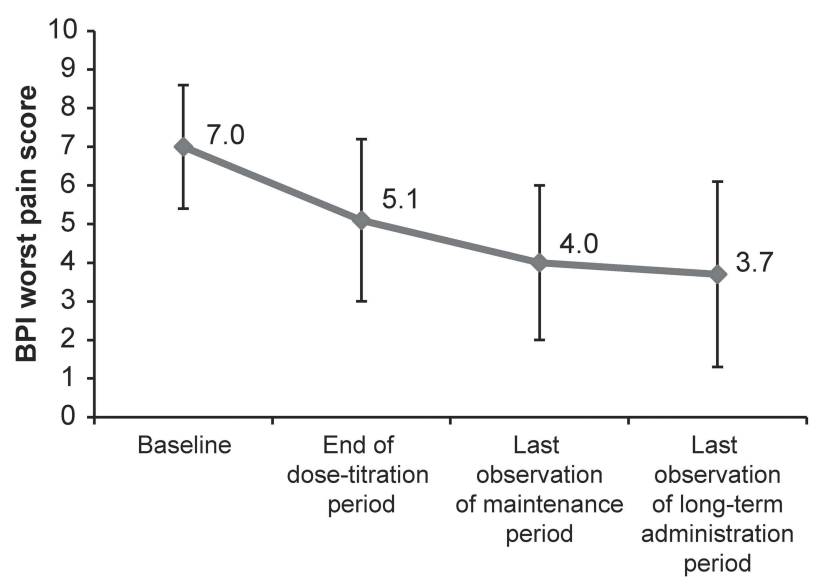

D

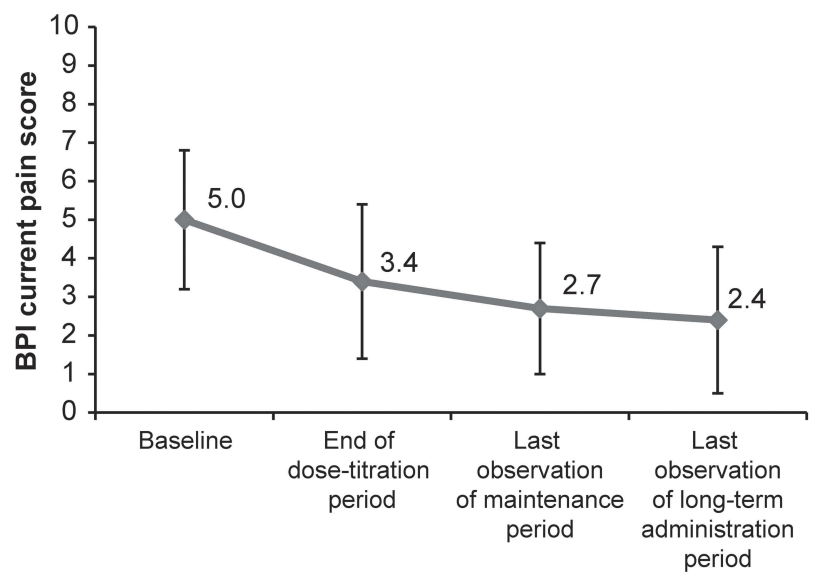

Figure 3 Change in mean BPI pain severity score (A) Average pain, (B) Worst pain, (C) Least pain, and (D) Current pain.

Note: Data are presented as mean \pm SD.

Abbreviations: BPI, Brief Pain Inventory; SD, standard deviation.

suggesting a decrease in pain severity and interference of pain with daily activities after treatment with S-8117 (Table 3). As compared to the end of the dose-titration period, the mean scores for the four BPI pain severity items and BPI pain interference for seven daily activities numerically decreased at the end of the maintenance period, suggesting that pain severity and interference of pain with daily activities further decreased during the maintenance period (Table 3).

The scores for all eight domains of SF-36 numerically increased from baseline at the end of the dose-titration period and last observation of the maintenance and long-term administration periods (Table 3) suggesting improvement in QOL. The overall WOMAC OA index score and that for all the three domains numerically decreased from baseline to the end of the dose-titration period and last observation of the maintenance and long-term administration periods suggesting decrease in pain, stiffness, and improvement in physical function in patients with OA (Table 3).

\section{Safety}

The majority (93.8\%) of patients reported TEAEs, with the incidence of TEAEs comparable across CNCP conditions (90.9-96.4\%; Table 4). Overall, 14 serious TEAEs were reported in 12 patients $(9.2 \%)$. The most commonly reported TEAEs were constipation (49.2\%), nausea $(42.3 \%)$, nasopharyngitis (34.6\%), and somnolence (32.3\%; Table 5). During the dose titration, maintenance, and long-term administration period, $76.9 \%(100 / 130), 52.6 \%$ (50/95), and $91.6 \%$ (76/83) of patients reported TEAEs, respectively. The most commonly reported TEAEs were constipation (33.8\%), nausea $(33.8 \%)$, somnolence $(23.8 \%)$, and vomiting $(11.5 \%)$ in 
Table 3 Secondary Efficacy Results

\begin{tabular}{|c|c|c|c|c|}
\hline Efficacy Measure, Mean士SD & $\begin{array}{l}\text { Baseline } \\
(n=\mid 30)\end{array}$ & $\begin{array}{l}\text { End of Dose- } \\
\text { Titration Period } \\
(n=130)\end{array}$ & $\begin{array}{l}\text { Last Observation Of } \\
\text { Maintenance Period } \\
(n=95)\end{array}$ & $\begin{array}{l}\text { Last Observation Of Long- } \\
\text { Term Administration Period } \\
(n=83)\end{array}$ \\
\hline \multicolumn{5}{|l|}{ BPI pain severity } \\
\hline $\mathrm{n}$ & 130 & 130 & 95 & 83 \\
\hline Average pain & $5.5 \pm 1.3$ & $3.6 \pm 1.7$ & $2.7 \pm 1.4$ & $2.6 \pm 1.8$ \\
\hline Worst pain & $7.0 \pm 1.6$ & $5.1 \pm 2.1$ & $4.0 \pm 2.0$ & $3.7 \pm 2.4$ \\
\hline Least pain & $3.3 \pm 1.7$ & $2.4 \pm 1.6$ & $1.8 \pm 1.3$ & $1.7 \pm 1.5$ \\
\hline Current pain & $5.0 \pm 1.8$ & $3.4 \pm 2.0$ & $2.7 \pm 1.7$ & $2.4 \pm 1.9$ \\
\hline \multicolumn{5}{|l|}{ BPI pain interference } \\
\hline $\mathrm{n}$ & 130 & 130 & 95 & 83 \\
\hline General activity & $5.4 \pm 2.1$ & $3.9 \pm 2.2$ & $2.8 \pm 2.2$ & $2.5 \pm 2.2$ \\
\hline Mood & $5.0 \pm 2.5$ & $3.1 \pm 2.4$ & $2.2 \pm 1.9$ & $2.2 \pm 2.2$ \\
\hline Walking ability & $4.7 \pm 3.0$ & $3.3 \pm 2.6$ & $2.5 \pm 2.4$ & $2.3 \pm 2.4$ \\
\hline Normal work & $5.3 \pm 2.5$ & $3.4 \pm 2.3$ & $2.4 \pm 2.0$ & $2.2 \pm 1.9$ \\
\hline Relationship with others & $3.7 \pm 2.7$ & $2.7 \pm 2.5$ & $1.8 \pm 2.0$ & $1.9 \pm 2.0$ \\
\hline Sleep & $4.3 \pm 2.9$ & $2.7 \pm 2.5$ & $1.8 \pm 2.0$ & $2.0 \pm 2.2$ \\
\hline Enjoyment of life & $4.9 \pm 2.7$ & $3.2 \pm 2.6$ & $2.1 \pm 2.0$ & $2.2 \pm 2.1$ \\
\hline Average of the 7 subscores & $4.77 \pm 2.14$ & $3.17 \pm 2.09$ & $2.23 \pm 1.85$ & $2.20 \pm 1.96$ \\
\hline \multicolumn{5}{|l|}{ SF-36 ${ }^{a}$} \\
\hline $\mathrm{n}$ & 130 & 129 & 91 & 82 \\
\hline Physical functioning & $48.19 \pm 25.81$ & $57.09 \pm 26.62$ & $62.53 \pm 26.31$ & $62.50 \pm 26.73$ \\
\hline Role physical & $50.05 \pm 25.72$ & $60.95 \pm 25.44$ & $65.66 \pm 23.07$ & $63.57 \pm 28.05$ \\
\hline Bodily pain & $33.46 \pm 13.75$ & $43.58 \pm 14.78$ & $51.02 \pm 14.32$ & $50.33 \pm 18.96$ \\
\hline General health & $45.13 \pm 17.26$ & $52.37 \pm 18.28$ & $52.86 \pm|5.6|$ & $51.17 \pm 17.35$ \\
\hline Vitality & $43.94 \pm 19.72$ & $53.15 \pm 20.10$ & $56.87 \pm 19.16$ & $51.60 \pm 19.98$ \\
\hline Social functioning & $58.37 \pm 25.21$ & $68.99 \pm 26.15$ & $75.14 \pm 22.7 \mid$ & $71.04 \pm 26.34$ \\
\hline Role emotional & $55.00 \pm 28.77$ & $66.47 \pm 27.86$ & $72.34 \pm 23.10$ & $71.34 \pm 28.18$ \\
\hline Mental health & $56.12 \pm 19.06$ & $64.53 \pm 20.06$ & $68.4 I \pm 18.90$ & $63.96 \pm 21.51$ \\
\hline \multicolumn{5}{|l|}{ WOMAC osteoarthritis index ${ }^{\mathrm{b}}$} \\
\hline $\mathrm{n}$ & 56 & 55 & 40 & 36 \\
\hline Pain & $9.79 \pm 3.19$ & $6.24 \pm 2.69$ & $5.58 \pm 2.63$ & $5.81 \pm 2.88$ \\
\hline Stiffness & $4.18 \pm 1.72$ & $2.82 \pm 1.43$ & $2.20 \pm 1.44$ & $2.47 \pm 1.38$ \\
\hline Physical function & $30.29 \pm 11.78$ & $19.18 \pm 9.90$ & $15.45 \pm 9.2 \mid$ & $17.28 \pm 10.50$ \\
\hline Total score & $44.25 \pm 15.38$ & $28.24 \pm 12.92$ & $23.23 \pm 12.47$ & $25.56 \pm 13.82$ \\
\hline
\end{tabular}

Notes: The analysis set used was FAS for baseline and the dose-titration period and FAS-2 for the maintenance and long-term administration periods. ${ }^{a}$ Baseline, $\mathrm{n}=\mathrm{I} 30$; end of dose-titration period, $n=129$; end of maintenance period, $n=91$; end of long-term administration period, $n=82$. ${ }^{b}$ The WOMAC osteoarthritis index was assessed only in patients with osteoarthritis (baseline, $n=56$; end of dose-titration period, $n=55$; end of maintenance period, $n=40$; end of long-term administration period, $n=36$ ).

Abbreviations: BPI, Brief Pain Inventory; FAS, full analysis set; SD, standard deviation; SF-36, 36-item Short Form Health Survey; WOMAC, Western Ontario and McMaster Universities.

the dose-titration period and nasopharyngitis (33.7\%), nausea $(13.3 \%)$, constipation $(12.0 \%)$, and vomiting $(10.8 \%)$ in the long-term administration period. All cases of constipation were treated with laxatives because peripherally acting muopioid receptor antagonists were not available in Japan at the time of this research. Overall, three serious TEAEs (pneumonia, sudden hearing loss, and hepatic cyst) were reported in the dose-titration period and 10 TEAEs (diabetes mellitus, pyelonephritis, cholelithiasis, hypoglycemia, gastrointestinal disorder, heat illness, sepsis, intestinal perforation, glaucoma, and femoral neck fracture) in the long-term administration period. No deaths were reported during the study.

\section{Withdrawal Symptoms And Drug Dependency}

In the dose-tapering and post-treatment observation periods, the mean \pm SD change in COWS in part 1 was $-0.5 \pm 2.0$ and $-0.7 \pm 1.3$ and in part 2 was $0.5 \pm 2.1$ and $0.1 \pm 0.7$, respectively. Similarly, in the dose-tapering and post-treatment 
Table 4 Safety Summary (Safety Analysis Set)

\begin{tabular}{|c|c|c|c|c|c|}
\hline TEAEs & $\begin{array}{l}\text { Total } \\
(n=130)\end{array}$ & $\begin{array}{l}\text { Osteoarthritis } \\
(n=56)\end{array}$ & $\begin{array}{l}\text { Diabetic } \\
\text { Neuropathic Pain } \\
(n=I I)\end{array}$ & $\begin{array}{l}\text { Post-Herpetic } \\
\text { Neuralgia }(n=28)\end{array}$ & $\begin{array}{l}\text { Other Chronic Pain } \\
\text { Conditions }(n=35)\end{array}$ \\
\hline \multicolumn{6}{|l|}{ TEAEs } \\
\hline Overall, n (\%) & $122(93.8)$ & $53(94.6)$ & $10(90.9)$ & $27(96.4)$ & 32 (91.4) \\
\hline Number of events & 672 & 278 & 53 & 119 & 222 \\
\hline \multicolumn{6}{|l|}{ Serious TEAEs } \\
\hline Overall, n (\%) & $12(9.2)$ & $5(8.9)$ & $3(27.3)$ & I (3.6) & $3(8.6)$ \\
\hline Number of events & 14 & 6 & 4 & I & 3 \\
\hline \multicolumn{6}{|l|}{ Significant TEAEs } \\
\hline Overall, n (\%) & $25(19.2)$ & $13(23.2)$ & I (9.1) & $4(14.3)$ & $7(20.0)$ \\
\hline Number of events & 36 & 20 & 1 & 4 & 11 \\
\hline \multicolumn{6}{|l|}{$\begin{array}{l}\text { TEAEs leading to study } \\
\text { drug discontinuation }\end{array}$} \\
\hline Overall, n (\%) & $29(22.3)$ & $15(26.8)$ & $2(18.2)$ & $4(14.3)$ & $8(22.9)$ \\
\hline Number of events & 43 & 24 & 2 & 5 & 12 \\
\hline
\end{tabular}

Abbreviation: TEAE, treatment-emergent adverse event.

observation periods, the mean \pm SD change in SOWS in part 1 was $-2.7 \pm 8.5$ and $-4.5 \pm 3.9$ and in part 2 was $-0.2 \pm 3.8$ and $0.8 \pm 7.7$, respectively. A total of 25 patients (D-2-A, 21 events in 15 patients; D-2-B, 15 events in 15 patients) had suspected drug dependency and were centrally reviewed by the Data and Safety Monitoring Board. However, none of them were judged to have developed drug dependency.

\section{Treatment Exposure}

The mean \pm SD daily $\mathrm{S}-8117$ dose at the end of the dosetitration, maintenance, and long-term administration periods was $34.9 \pm 22.0,33.12 \pm 21.98$, and $36.44 \pm 24.11 \mathrm{mg}$, respectively. The mean daily dose was higher in patients with other chronic pain conditions (44.9-54.35 mg) compared to those with OA, DNP, or PHN (22.21-32.46 mg) at the end of the dose-titration, maintenance, and longterm administration periods.

\section{Discussion}

In this phase 3 study, we assessed the efficacy and safety of S-8117 in Japanese patients with various underlying conditions of CNCP including OA, DNP, PHN, and other CNCP conditions. During the maintenance period, the proportion of patients with successful maintenance of analgesic effect was $78.9 \%$ suggesting effective pain control with S-8117. The BPI, SF-36, and WOMAC OA index scores over the study periods demonstrated pain relief and improvement in QOL and daily physical functioning among patients with CNCP after treatment with S-8117.
In our previous study, $21.0 \%$ of Japanese patients with CLBP (21.0\%) showed inadequate analgesia with S-8117, ${ }^{25}$ which is similar to the discontinuation rate due to inadequate analgesia or AEs in the current study (21.1\%). These results indicate similar analgesic effect of S-8117 in Japanese patients with CNCP due to CLBP, OA, DNP, PHN, and other CNCP conditions. The current study results were also consistent with previous studies outside of Japan in which patients with various CNCP conditions ${ }^{18-21}$ achieved pain relief with $\mathrm{CR}$ oxycodone tablets. In our study, treatment with S-8117 was also associated with an improvement in QOL and daily physical functioning in patients with $\mathrm{CNCP}$, which is in line with results from a previous randomized, controlled, clinical study of CR oxycodone tablets in non-Japanese OA patients. ${ }^{34}$

During the entire study period, the most commonly reported TEAEs were constipation (49.2\%), nausea $(42.3 \%)$, nasopharyngitis (34.6\%), and somnolence $(32.3 \%)$, with gastrointestinal disorders being the most common TEAEs in both the dose-titration and long-term administration periods. Moreover, treatment with S-8117 did not lead to clinically significant withdrawal syndrome or drug dependence in Japanese patients with CNCP in the current study, which is consistent with that observed in our previous study in Japanese CLBP patients. ${ }^{25}$ This suggests that careful patient monitoring could potentially prevent withdrawal syndrome and drug dependence in patients receiving S-8117. No new safety concerns were observed. These safety results are consistent with those from the 
Table 5 TEAEs By System Organ Class (Overall Incidence $\geq 5 \%$ ) And Preferred Term (Safety Analysis Set)

\begin{tabular}{|c|c|c|c|c|c|}
\hline TEAEs, n (\%) & $\begin{array}{l}\text { Total } \\
(n=130)\end{array}$ & $\begin{array}{l}\text { Osteoarthritis } \\
(n=56)\end{array}$ & $\begin{array}{l}\text { Diabetic } \\
\text { Neuropathic } \\
\text { Pain }(n=I \text { I) }\end{array}$ & $\begin{array}{l}\text { Post-Herpetic } \\
\text { Neuralgia } \\
(n=28)\end{array}$ & $\begin{array}{l}\text { Other Chronic } \\
\text { Pain Conditions } \\
(n=35)\end{array}$ \\
\hline Overall & $122(93.8)$ & $53(94.6)$ & $10(90.9)$ & $27(96.4)$ & $32(91.4)$ \\
\hline Gastrointestinal disorders & $96(73.8)$ & $45(80.4)$ & $9(81.8)$ & $16(57.1)$ & $26(74.3)$ \\
\hline Constipation & $64(49.2)$ & 31 (55.4) & $7(63.6)$ & $10(35.7)$ & $16(45.7)$ \\
\hline Nausea & $55(42.3)$ & $28(50.0)$ & $4(36.4)$ & $5(17.9)$ & $18(51.4)$ \\
\hline Vomiting & $22(16.9)$ & $9(16.1)$ & $2(18.2)$ & $3(10.7)$ & $8(22.9)$ \\
\hline Diarrhea & II (8.5) & $5(8.9)$ & I (9.I) & $2(7.1)$ & $3(8.6)$ \\
\hline Nervous system disorders & $59(45.4)$ & $23(4 I .1)$ & $3(27.3)$ & II (39.3) & $22(62.9)$ \\
\hline Somnolence & $42(32.3)$ & $20(35.7)$ & 0 & $10(35.7)$ & $12(34.3)$ \\
\hline Dizziness & $10(7.7)$ & $3(5.4)$ & 0 & $2(7.1)$ & $5(14.3)$ \\
\hline Headache & $8(6.2)$ & $\mathrm{I}(\mathrm{I} .8)$ & I (9.1) & 0 & $6(17.1)$ \\
\hline Infections and infestations & $56(43.1)$ & $21(37.5)$ & $3(27.3)$ & $18(64.3)$ & $14(40.0)$ \\
\hline Nasopharyngitis & $45(34.6)$ & $18(32.1)$ & $2(18.2)$ & $13(46.4)$ & $12(34.3)$ \\
\hline Musculoskeletal and connective tissue disorders & $35(26.9)$ & $16(28.6)$ & $3(27.3)$ & $7(25.0)$ & $9(25.7)$ \\
\hline Back pain & $7(5.4)$ & $3(5.4)$ & 0 & 0 & $4(11.4)$ \\
\hline $\begin{array}{l}\text { General disorders and administration site } \\
\text { conditions }\end{array}$ & $34(26.2)$ & $14(25.0)$ & $3(27.3)$ & $7(25.0)$ & $10(28.6)$ \\
\hline Drug withdrawal syndrome & $9(6.9)$ & $4(7.1)$ & I (9.1) & $2(7.1)$ & $2(5.7)$ \\
\hline Malaise & $8(6.2)$ & $5(8.9)$ & 0 & I (3.6) & $2(5.7)$ \\
\hline Skin and subcutaneous tissue disorders & $30(23.1)$ & $12(21.4)$ & I (9.1) & $7(25.0)$ & $10(28.6)$ \\
\hline Pruritus & $12(9.2)$ & $3(5.4)$ & I (9.1) & $5(17.9)$ & $3(8.6)$ \\
\hline Eczema & $10(7.7)$ & $5(8.9)$ & I (9.1) & $2(7.1)$ & $2(5.7)$ \\
\hline Injury, poisoning and procedural complications & $24(18.5)$ & $8(14.3)$ & $4(36.4)$ & $5(17.9)$ & $7(20.0)$ \\
\hline Contusion & $10(7.7)$ & $3(5.4)$ & I (9.1) & $2(7.1)$ & $4(11.4)$ \\
\hline Metabolism and nutrition disorders & $19(14.6)$ & $9(16.1)$ & $4(36.4)$ & I (3.6) & $5(14.3)$ \\
\hline Decreased appetite & $10(7.7)$ & $6(10.7)$ & I (9.1) & 0 & $3(8.6)$ \\
\hline Psychiatric disorders & $16(12.3)$ & $6(10.7)$ & $2(18.2)$ & $4(14.3)$ & $4(I I .4)$ \\
\hline Insomnia & II (8.5) & $5(8.9)$ & $2(18.2)$ & $3(10.7)$ & I (2.9) \\
\hline Investigations & $16(12.3)$ & $7(12.5)$ & $3(27.3)$ & $3(10.7)$ & $3(8.6)$ \\
\hline Aspartate aminotransferase increased & $4(3.1)$ & $\mathrm{I}(\mathrm{I} .8)$ & 0 & 0 & $3(8.6)$ \\
\hline Weight decreased & $3(2.3)$ & $2(3.6)$ & 0 & I (3.6) & 0 \\
\hline Respiratory, thoracic and mediastinal disorders & II (8.5) & $\mathrm{I}(\mathrm{I} .8)$ & I (9.1) & $3(10.7)$ & $6(17.1)$ \\
\hline Oropharyngeal pain & $3(2.3)$ & 0 & 0 & $2(7.1)$ & I (2.9) \\
\hline
\end{tabular}

Abbreviation: TEAE, treatment-emergent adverse event.

concurrently performed study in patients with $\mathrm{CLBP}^{25}$ and previous overseas studies. ${ }^{18,21,35-37}$

In the current study, patients with a history of drug dependency and patients whose major cause of pain was associated with psychosocial factors (BS-POP score of $\geq 11$ ) were excluded based on pre-dose risk assessments for drug dependency. The BS-POP was developed by Japanese researchers as a tool to assess the association of psychosocial factors with pain in a convenient manner. ${ }^{28}$ As past or current substance abuse and untreated psychiatric disorders are typical risk factors for opioid dependency, ${ }^{38}$ exclusion of such patients at baseline may have contributed to the absence of drug dependency in the enrolled population.

It should also be noted that the currently available opioid dependency measures in Japan, including the D-2A and D-2-B questionnaires used in this study, are not 
validated. Historically, in Japan, it has been difficult to develop evaluation tools for drug dependency as the incidence of opioid dependency or abuse is extremely low in Japan compared with Western countries, owing to the tightly regulated opioid management system. In the current study, we adopted the D-2-A and D-2-B questionnaires as they had been used in several previous clinical trials in Japan to assess drug dependency. ${ }^{33}$

Although the efficacy of $\mathrm{CR}$ oxycodone tablets has been previously demonstrated in patients with CNCP due to various causes, ${ }^{18-21}$ the potential risk of abuse, overdose, or misuse among opioid users is a cause of concern when prescribing strong opioids for CNCP management. ${ }^{7,8,39}$ Moreover, opioid-induced AEs (eg, constipation, nausea, and vomiting) can also lead to treatment discontinuation, increased treatment costs, and additional healthcare burden. ${ }^{40,41}$ In our study, nearly half of the patients experienced constipation or nausea as TEAEs during the study, and approximately $20 \%$ of the patients discontinued treatment due to AEs. Thus, appropriate management of AEs is warranted in patients with CNCP who are prescribed oxycodone in routine clinical practice as in the case of other opioids.

We enrolled patients aged $\geq 20$ to $<80$ years in this study to include all the age groups in which oxycodone may be used for the management of CNCP. Concerns associated with opioid use vary with age. For example, decreased drug metabolism and excretion in the elderly generally lead to drug accumulation in the body. ${ }^{42}$ For young adults, it is widely acknowledged that they are prone to various opioid-associated risks such as drug dependency. ${ }^{43}$ In addition, results from a recent observational study in Japan implied that the cumulative incidence of opioid-induced constipation in patients with cancer pain was numerically higher in those with lower age $(77 \%$ in patients aged $\geq 40$ to $<50$ years vs. $49 \%$ in patients aged $\geq 75$ years), although the results were not statistically significant. ${ }^{44}$ The results of our single trial may not be sufficient to establish the efficacy and safety of oxycodone in different age groups, and further research is needed.

Our study has several limitations: (i) the efficacy and safety of S-8117 were assessed in a controlled patient population so the results may not be extrapolatable to daily clinical practice; (ii) a 1-year follow-up period may be insufficient to assess possible drug dependence associated with long-term use of S-8117; and (iii) patients were assessed for drug dependence in a clinical trial setting that involved meticulous patient selection and continuous monitoring; thus, results cannot be generalized to realworld settings. Therefore, careful patient selection and vigilant monitoring remain crucial to maximize the benefit of S-8117.

\section{Conclusion}

This is one of the first studies to demonstrate the analgesic effect of S-8117 and confirm its tolerability during longterm administration in Japanese patients with CNCP. The study results suggest that $\mathrm{S}-8117$ is a potential treatment option in Japanese patients with CNCP.

\section{Abbreviations}

AE, adverse event; BPI, Brief Pain Inventory; BS-POP, Brief Scale for Psychiatric Problems in Orthopaedic Patients; CI, confidence interval; CLBP, chronic low back pain; CNCP, chronic non-cancer pain; COWS, Clinical Opioid Withdrawal Scale; CR, controlled release; D-2-A, Dependency-2-A; D-2-B, Dependency-2-B; DNP, diabetic neuropathic pain; FAS, full analysis set; KM, KaplanMeier; OA, osteoarthritis; PHN, post-herpetic neuralgia; QOL, quality of life; SD, standard deviation; SF-36, 36item Short Form Health Survey; SOWS, Subjective Opioid Withdrawal Scale; TEAE, treatment-emergent adverse event; US, United States; WOMAC, Western Ontario and McMaster Universities.

\section{Ethics Approval And Informed Consent}

This study was conducted in compliance with the Declaration of Helsinki (1996), Good Clinical Practice guidelines, and the Ministry of Health, Labour and Welfare, Japan, Ordinance No. 24. Additionally, the local ethics committee (institutional review boards) (Table S2) approved the study protocol. Written informed consent was solicited from all study participants before enrollment into the study.

\section{Data Availability (Where Applicable)}

- Whether the authors intend to share individual deidentified participant data: No

- What specific data they intend to share: Not available

- What other study-related documents will be made available: Not available

- How the data will be accessible: Not applicable

- When and for how long they will be made available: Not applicable 
In order to provide public data access pertaining to the Shionogi-sponsored studies on the approved products, a data-sharing system is currently under development along with a corresponding policy. For further inquiry, please contact Takuma Sasaki at takuma.sasaki@shionogi.co.jp

\section{Acknowledgments}

Data management, statistical analysis of the data, and reporting of the study were conducted by Shionogi \& Co., Ltd., Japan. We thank Dr. Deepali Garg, MBBS, PGDHA, of Cactus Communications, for writing, editorial, and graphics support, which was funded by Shionogi \& Co., Ltd., Japan.

\section{Author Contributions}

All named authors meet the International Committee of Medical Journal Editors (ICMJE) criteria for authorship for this manuscript, take responsibility for the integrity of the work as a whole, and have given final approval to the version to be published. All authors had full access to all the data in this study and take complete responsibility for the integrity of the data and accuracy of the data analysis. All authors contributed toward data analysis, drafting and revising the paper and agree to be accountable for all aspects of the work.

\section{Funding}

This study was funded by Shionogi \& Co., Ltd., Japan.

\section{Disclosure}

Mikito Kawamata received personal fees from Shionogi \& Co., Ltd., research grant from Otsuka Pharmaceutical Co., Ltd., and both personal fees and research grant from Nippon Zoki Pharmaceutical Co., Ltd. Shin-ichi Kikuchi received a grant from Shionogi \& Co., Ltd., and personal fees from Shionogi \& Co., Ltd., and Japan Agency for Medical Research and Development. Masako Iseki and Mamoru Kawakami received grants and personal fees from Shionogi \& Co., Ltd. Shoji Yabuki received personal fees from Pfizer Japan Inc., and both personal fees and research grants from Shionogi \& Co., Ltd., and Janssen Pharmaceutical K. K. Mitsuhiro Ishida, Takuma Sasaki, and Hideaki Hida are employees and shareholders of Shionogi \& Co., Ltd. Atsushi Nishiyori is an employee of Shionogi \& Co., Ltd. The authors report no other conflicts of interest in this work.

\section{References}

1. Inoue S, Kobayashi F, Nishihara M, et al. Chronic pain in the Japanese community-prevalence, characteristics and impact on quality of life. PLoS One. 2015;10(6):e0129262. doi:10.1371/journal.pone.0129262

2. Dahlhamer J, Lucas J, Zelaya C, et al. Prevalence of chronic pain and high-impact chronic pain among adults - United States, 2016. MMWR Morb Mortal Wkly Rep. 2018;67(36):1001-1006. doi:10.15585/mmwr. $\mathrm{mm} 6736 \mathrm{a} 2$

3. Shupler MS, Kramer JK, Cragg JJ, Jutzeler CR, Whitehurst DGT. Pan-Canadian estimates of chronic pain prevalence from 2000 to 2014: a repeated cross-sectional survey analysis. J Pain. 2018. pii: S1526-5900(18)30581-9. Epub ahead of print.

4. Nakata K, Tsuji T, Vietri J, Jaffe DH. Work impairment, osteoarthritis, and health-related quality of life among employees in Japan. Health Qual Life Outcomes. 2018;16(1):64. doi:10.1186/s12955-018-0896-9

5. Takura T, Ushida T, Kanchiku T, et al. The societal burden of chronic pain in Japan: an internet survey. J Orthop Sci. 2015;20(4):750-760. doi:10.1007/s00776-015-0730-8

6. Tsuji T, Matsudaira K, Sato H, Vietri J, Jaffe DH. Association between presenteeism and health-related quality of life among Japanese adults with chronic lower back pain: a retrospective observational study. $B M J$ Open. 2018;8(6):e021160. doi:10.1136/bmjopen-2017-021160

7. The Committee for the Guidelines for Prescribing Opioid Analgesics for Chronic Non-cancer Pain of JSPC. Japan Society of Pain Clinicians. Guidelines for Prescribing Opioid Analgesics for Chronic Non-Cancer Pain. 2nd ed. Japan: Shinko Trading Co., Ltd Publication Department of Medical Books. Accessed December 11, 2018.

8. Finnerup NB, Attal N, Haroutounian S, et al. Pharmacotherapy for neuropathic pain in adults: a systematic review and meta-analysis. Lancet Neurol. 2015;14(2):162-173. doi:10.1016/S1474-4422(14)70251-0

9. Dowell D, Haegerich TM, Chou R. CDC guideline for prescribing opioids for chronic pain - United States, 2016. MMWR Recomm Rep. 2016;65(1):1-49. doi:10.15585/mmwr.rr6501e1

10. Benyamin R, Trescot AM, Datta S, et al. Opioid complications and side effects. Pain Physician. 2008;11(2 Suppl):S105-120.

11. Narcotics and Psychotropics Control Act. Amendment of Act No. 50 of 2015. [Translate November 7, 2016]. Available from: http://www. japaneselawtranslation.go.jp/?re=02. Accessed December 11, 2018.

12. Onishi E, Kobayashi T, Dexter E, Marino M, Maeno T, Deyo RA. Comparison of opioid prescribing patterns in the United States and Japan: primary care physicians' attitudes and perceptions. J Am Board Fam Med. 2017;30(2):248-254. doi:10.3122/jabfm.2017.02.160299

13. Okumura Y, Sakata N, Takahashi K, Nishi D, Tachimori H. Epidemiology of overdose episodes from the period prior to hospitalization for drug poisoning until discharge in Japan: an exploratory descriptive study using a nationwide claims database. J Epidemiol. 2017;27(8):373-380. doi:10.1016/j.je.2016.08.010

14. U.S. Department of Health and Human Services. Substance Abuse and Mental Health Services Administration, Drug Abuse Warning Network, 2011: National Estimates of Drug-Related Emergency Department visits. HHS Publication No. (SMA) 13-4760, DAWN Series D-39. Rockville, MD. Available from: https://www.samhsa. gov/data/sites/default/files/DAWN2k11ED/DAWN2k11ED/ DAWN2k11ED.pdf. Accessed January 11, 2019.

15. Purdue Pharma LP. OxyContin ${ }^{\circledR}$ [package insert]. Available from: http://app.purduepharma.com/xmlpublishing/pi.aspx?id=o. Accessed January 4, 2019.

16. Schmidt-Hansen M, Bennett MI, Arnold S, Bromham N, Hilgart JS. Oxycodone for cancer-related pain. Cochrane Database Syst Rev. 2017;8:CD003870. doi:10.1002/14651858.CD003870.pub6

17. Narabayashi M, Saijo Y, Takenoshita S, et al. Opioid rotation from oral morphine to oral oxycodone in cancer patients with intolerable adverse effects: an open-label trial. Jpn J Clin Oncol. 2008;38 (4):296-304. doi:10.1093/jjco/hyn010 
18. Fan BF. Postmarketing surveillance study of OxyContin tablets for relieving moderate to severe postherpetic neuralgia pain. Oncology. 2008;74(Suppl 1):66-71. doi:10.1159/000143222

19. Friedmann N, Klutzaritz V, Webster L. Long-term safety of Remoxy ${ }^{\circledR}$ (extended-release oxycodone) in patients with moderate to severe chronic osteoarthritis or low back pain. Pain Med. 2011;12(5):755760. doi:10.1111/j.1526-4637.2011.01100.x

20. Friedmann N, Klutzaritz V, Webster L. Efficacy and safety of an extended-release oxycodone (Remoxy) formulation in patients with moderate to severe osteoarthritic pain. J Opioid Manag. 2011;7 (3):193-202. doi:10.5055/jom.2011.0062

21. Yao P, Meng LX, Ma JM, et al. Sustained-release oxycodone tablets for moderate to severe painful diabetic peripheral neuropathy: a multicenter, open-labeled, postmarketing clinical observation. Pain Med. 2012;13(1):107-114. doi:10.1111/j.1526-4637.2011.01274.x

22. Dart RC, Surratt HL, Cicero TJ, et al. Trends in opioid analgesic abuse and mortality in the United States. NEngl J Med. 2015;372(3):241-248. doi:10.1056/NEJMsa1406143

23. Warner M, Trinidad JP, Bastian BA, Minino AM, Hedegaard H. Drugs most frequently involved in drug overdose deaths: United States, 2010-2014. Natl Vital Stat Rep. 2016;65(10):1-15.

24. Coplan PM, Chilcoat HD, Butler SF, et al. The effect of an abusedeterrent opioid formulation (OxyContin) on opioid abuse-related outcomes in the postmarketing setting. Clin Pharmacol Ther. 2016;100(3):275-286. doi:10.1002/cpt.390

25. Kawamata M, Iseki M, Kawakami M, et al. Efficacy and safety of controlled-release oxycodone for the management of moderate-tosevere chronic low back pain in Japan: results of an enriched enrollment randomized withdrawal study followed by an open-label extension study. J Pain Res. 2019;12:363-375. doi:10.2147/JPR.S179110

26. Tsuji T, Ushida K, Arai K, et al. Standard nerve treatment: chronic pain (in Japanese). Neurol Ther. 2010;27(4):593-622.

27. Cleeland CS. Measurement of pain by subjective report. In: Chapman CR, Loeser JD, editors. Advances in Pain Research and Therapy: Issues in Pain Measurement. New York: Raven Press; 1989:391-403.

28. Yoshida K, Sekiguchi M, Otani K, et al. A validation study of the Brief Scale for Psychiatric problems in Orthopaedic Patients (BSPOP) for patients with chronic low back pain (verification of reliability, validity, and reproducibility). J Orthop Sci. 2011;16(1):7-13. doi: 10.1007/s00776-010-0012-4

29. Lins L, Carvalho FM. SF-36 total score as a single measure of healthrelated quality of life: scoping review. SAGE Open Med. 2016;4:2050312116671725. doi:10.1177/2050312116671725

30. Bellamy N, Buchanan WW, Goldsmith CH, Campbell J, Stitt LW. Validation study of WOMAC: a health status instrument for measuring clinically important patient relevant outcomes to antirheumatic drug therapy in patients with osteoarthritis of the hip or knee. J Rheumatol. 1988;15(12):1833-1840.
31. Handelsman L, Cochrane KJ, Aronson MJ, Ness R, Rubinstein KJ, Kanof PD. Two new rating scales for opiate withdrawal. Am J Drug Alcohol Abuse. 1987;13(3):293-308. doi:10.3109/00952998709001515

32. Wesson DR, Ling W. The Clinical Opiate Withdrawal Scale (COWS). J Psychoactive Drugs. 2003;35(2):253-259. doi:10.1080/ 02791072.2003.10400007

33. Kurihara M, Jimbo M, Hirose T, et al. Double-blind comparison of clinical effects of ID-540 (fludiazepam), diazepam and placebo on psychoneurotic patients and a tentative draft of dependency questionnaire. Rinsho Hyoka. 1977;5(2):341-368

34. Markenson JA, Croft J, Zhang PG, Richards P. Treatment of persistent pain associated with osteoarthritis with controlled-release oxycodone tablets in a randomized controlled clinical trial. Clin J Pain. 2005;21(6):524-535. doi:10.1097/01.ajp.0000146215.86038.38

35. Els C, Jackson TD, Kunyk D, et al. Adverse events associated with medium- and long-term use of opioids for chronic non-cancer pain: an overview of Cochrane Reviews. Cochrane Database Syst Rev. 2017;10:CD012509. doi:10.1002/14651858.CD012509.pub2

36. Kopecky EA, Vaughn B, Lagasse S, O’Connor M. Tolerability, safety, and effectiveness of oxycodone DETERx in elderly patients $\geq 65$ years of age with chronic low back pain: a randomized controlled trial. Drugs Aging. 2017;34(8):603-613. doi:10.1007/s40266-017-0473-7

37. Portenoy RK, Farrar JT, Backonja MM, et al. Long-term use of controlled-release oxycodone for noncancer pain: results of a 3-year registry study. Clin J Pain. 2007;23(4):287-299. doi:10.1097/ AJP.0b013e31802b582f

38. Webster LR. Risk factors for opioid-use disorder and overdose. Anesth Analg. 2017;125(5):1741-1748. doi:10.1213/ANE.0000000000002496

39. Edlund MJ, Martin BC, Russo JE, DeVries A, Braden JB, Sullivan MD. The role of opioid prescription in incident opioid abuse and dependence among individuals with chronic noncancer pain: the role of opioid prescription. Clin J Pain. 2014;30(7):557-564. doi:10.1097/AJP.0000000000000021

40. Nicholson BD. Economic and clinical burden of opioid-induced nausea and vomiting. Postgrad Med. 2017;129(1):111-117. doi:10.10 80/00325481.2017.1243004

41. Wan Y, Corman S, Gao X, Liu S, Patel H, Mody R. Economic burden of opioid-induced constipation among long-term opioid users with noncancer pain. Am Health Drug Benefits. 2015;8(2):93-102.

42. Chau DL, Walker V, Pai L, Cho LM. Opiates and elderly: use and side effects. Clin Interv Aging. 2008;3(2):273-278. doi:10.2147/CIA. S1847

43. Borodovsky JT, Levy S, Fishman M, Marsch LA. Buprenorphine treatment for adolescents and young adults with opioid use disorders: a narrative review. J Addict Med. 2018;12(3):170-183. doi:10.1097/ ADM.0000000000000388

44. Tokoro A, Imai H, Fumita S, et al. Incidence of opioid-induced constipation in Japanese patients with cancer pain: a prospective observational cohort study. Cancer Med. 2019;8(10):4883-4891. doi:10.1002/cam4.2341
Journal of Pain Research

\section{Publish your work in this journal}

The Journal of Pain Research is an international, peer reviewed, open access, online journal that welcomes laboratory and clinical findings in the fields of pain research and the prevention and management of pain. Original research, reviews, symposium reports, hypothesis formation and commentaries are all considered for publication. The manuscript management system is completely online and includes a very quick and fair peer-review system, which is all easy to use. Visit http:// www.dovepress.com/testimonials.php to read real quotes from published authors. 